\title{
海外でも評価された日本の照明デザイン2013/2014＼cjkstart特集趣旨
}

IALD（国際照明デザイナー協会）とIES（北米照明学会）の照明デザイン賞には世界中の照明デザイナーがその 作品を応募するため，そこで受賞された作品は海外でも評価された日本の照明デザインといえます．

一昨年に引き続き，本特集では，2013，2014年度の受賞作品についてコンセプトや留意点，工夫した点などを図 や写真で解説いただきました，照明デザイン業務に携わっている方，志す方に参考となれば幸いです．

\section{<本号掲載作品と執筆者 $>$}

2013年の IALD International Lighting Design Awards の受賞は 1 件，2014年は 4 件でした．2013年の IES Illumination Awards の受賞は37件，2014年は28件と受賞作品が多く，全ての作品をご紹介することができませんでしたＩALD に関しては2013年, 2014年の両年度の受賞作品, IES に関しては, 2013年は Award of Merit より上位の受賞作品, 2014年は Award of Merit の受賞作品内から，1社で 1 作品として選定させていただきました。

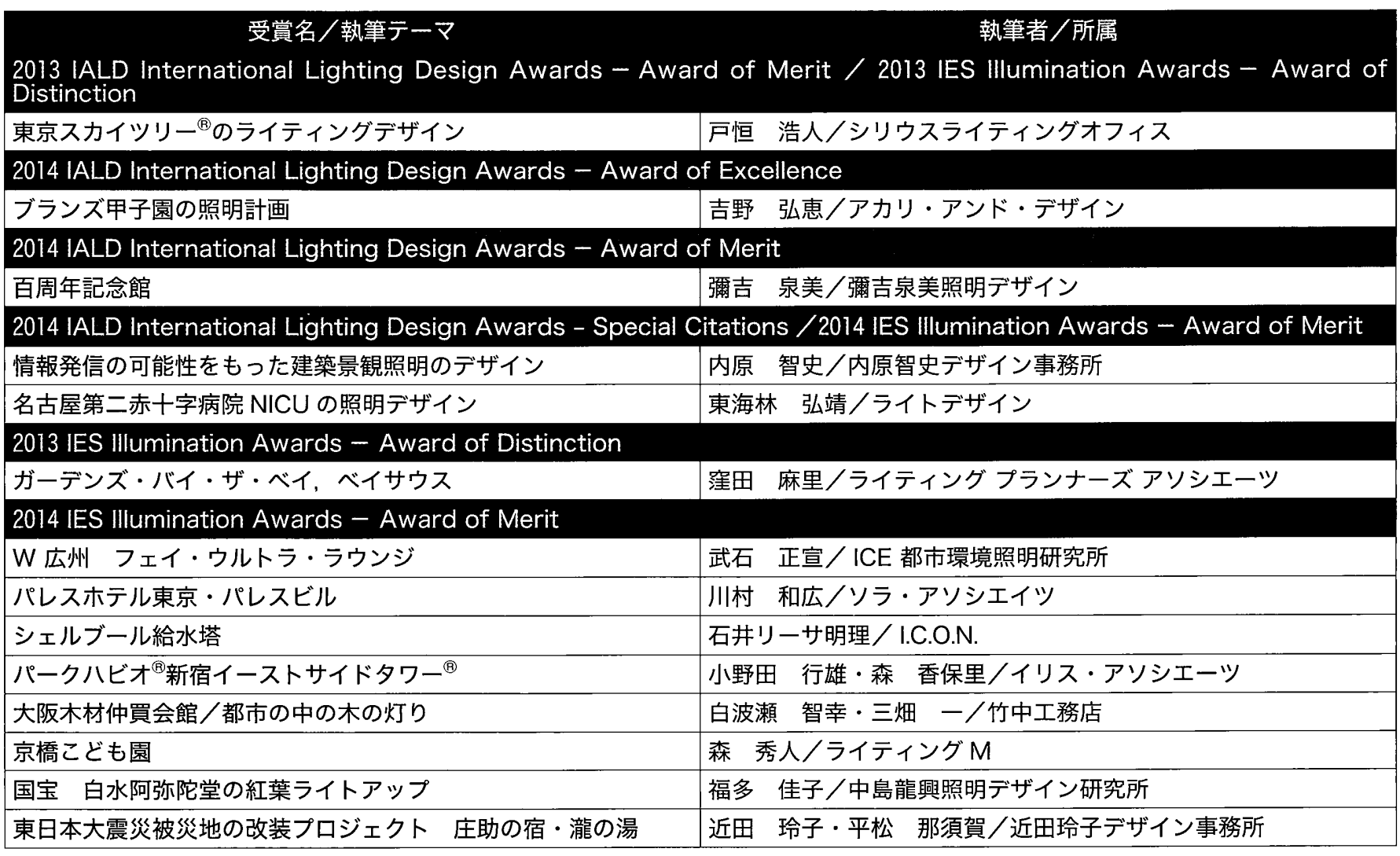

照明学会の普及賞とのダブル受賞作品や既に学会誌にて揭載されている作品などに関しては，本号には揭載され ていませんが, 次の方々も各賞を受賞されました。受賞作品名と受賞筆頭者名，既に紹介している作品に関しては 掲載号を紹介させていただきます。

\section{受賞名/受賞作品名}

揭載号

2013 IES Illumination Awards - Award of Excellence

TOKYO GATE BRIDGE

ISE SHRINE SENGU MUSEUM

2013 IES Illumination Awards - Award of Merit

ARK HILLS SENGOKUYAMA MORI TOWER

BOOKSHELF LIGHTING FOR LIBRARY OF ICHINOMIYA CITY

BUNGOTAKADA CITY LIBRARY

CHENMAPO-DOUFU AKASAKA ARK HILLS SHOP

CHUSON-JI KONJIKIDO

COURT HOUSE IN TOKYO

DOJIMA BRIDGE

\section{受賞筆頭者}


2013 IES Illumination Awards - Award of Merit

GLA YATSUGATAKE INOCHINOSATO LIFE MEMORIAL HALL

GREAT NATURE AT NABANA-NO-SATO PARK

HARAJUKU JINGU NO MORI

HOSHINO-YA TAKETOMIJIMA

ITO INTERNATIONAL RESEARCH CENTER AND ITO HALL, THE UNIVERSITY OF TOKYO

KARUIZAWA MUSEUM COMPLEX

KASUMIGASEKI LIVE OFFICE "NEXT OFFFICE"

KOKUYO SHANGHAI FLAGHIP SHOWROOM

LIGHTING FOR NAKANOSHIMA FESTIVAL TOWER

LIXIL MUSEUM

NAKANO CENTRAL PARK SOUTH

REFLECTIONS AT KEPPEL BAY

RENOVATION OF NANKAI TERMINAL BUILDING

SAIHOJI TEMPLE

SAINOKUNI SAITAMA ARTS THEATER

SHARE YARAICHO

SHINJUKU EASTSIDE SQUARE

SPECIAL LIGHT EVENT-SOENE AKARI PARK

TECHNICAL CENTER

THE LCCM (LIFE CYCLE CARBON MINUS) DEMONSTRATION HOUSE

THE STAR PERFORMING ARTS CENTRE \& STAR VISTA

THE SUMIDA AQUARIUM : PENGUIN TANK

TOKYO METROPOLITAN THEATRE

TOKYO STATION MARUNOUCHI BUILDING

VERMILLON BAGUE

YAOKO KAWAGOE MUSEUM

2014 IES Illumination Awards - Award of Merit

ABENO HARUKAS

AICHI DENTAL ASSOCIATION OFFICE

ARTS MAEBASHI

CHUSON-JI SANKOZO

GALAXY SOHO

HAPPO-EN MAIN ENTRANCE LOBBY RENOVATION PROJECT

INTERCONTINENTAL OSAKA

KABUKI THEATER

MARK IS MINATOMIRAI

PARKROYAL ON PICKERING

PAS DE CALAIS SOHO, NEW YORK GLOBAL FLAGSHIP STORE

ROPPONGI HILLS 10TH ANNIVERSARY CHRISTMAS

SILVER MOUNTAIN \& RED CLIFF

STANLEY ELECTRIC CO., LTD. NEW HEAD OFFICE BUILDING

THE INTERLACE

THE WESTMINSTER ROPPONGI

TOYOHASHI ARTS THEATRE PLAT

WORLD HERITAGE MT.FUJI AT NABANA-NO-SATO PARK 2013

\begin{tabular}{|c|c|}
\hline Masanobu Takeishi & \\
\hline Masaki Kawase & Vol.97, No.1 \\
\hline Ryuichi Sawada & \\
\hline
\end{tabular}

Ryuichi Sawada

Masanobu Takeishi

Hideto Mori

Hideo Yasui

Kazuhiko Suzuki

Masanobu Takeishi

Ryuji Hotta

Vol.98, №.1

Kazuhiko Suzuki

Satoshi Uchihara

Kaoru Mende

Satoshi Uchihara

Saika Okamura

Hideto Mori

Reiko Chikada

Kazuhiro Kawamura

Motoko Ishii

Hideto Mori

Susumu Matsushita

Kaoru Mende

Masanobu Takeishi

Reiko Chikada

Vol.98, №.7

Kaoru Mende

Vol.98, №.7

Masanobu Takeishi

Hiroyasu Shoji

*揭載号の執筆者は受賞者とは異なる場合も含めています. 